\title{
PENGARUH PENERAPAN PEMBELAJARAN AKTIF TIPE HOLLYWOOD SQUARES MENGGUNAKAN LKS TERHADAP HASIL BELAJAR GEOGRAFI SISWA KELAS XI IPS SMAN I SUTERA KABUPATEN PESISIR SELATAN
}

\author{
Fitri Rahmadani ${ }^{1}$, Syafri Anwar ${ }^{2}$, Nofrion $^{2}$ \\ Program Studi Pendidikan Geografi, \\ Fakultas Ilmu Sosial, Universitas Negeri Padang \\ Email: vivit.sikumbang@gmail.com
}

\begin{abstract}
Abstrak
Tujuan dari penelitian untuk mengetahui pengaruh penerapan pembelajaran aktif tipe Hollywood Squares menggunakan LKS terhadap hasil belajar geografi siswa kelas XI IPS SMAN 1 Sutera Kabupaten Pesisir Selatan.Hipotesis dalam penelitian ini adalah "Terdapat pengaruh yang berarti penerapan pembelajaran aktif tipe Hollywood Squares menggunakan LKS terhadap hasil belajar geografi siswa kelas XI SMAN 1 Sutera Kabupaten Pesisir Selatan".Jenis penelitian ini adalah ekperimen semu, dengan rancangan randomizedcontrol only design. Populasi dalam penelitian ini adalah siswa kelas XI IPS SMAN 1 Sutera Kabupaten Pesisir Selatan yang terdaftar tahunajaran 2016/2017, sampel terpilih dengan menggunakan teknik cluster random sampling, dimana terpilih kelas XI $\mathrm{IPS}_{2}$ sebagai kelas kontrol dan kelas XI IPS ${ }_{1}$ sebagai kelas eksperimen. Untuk uji hipotesis digunakan uji kesamaan dua rata-rata $(\mathrm{t})$ pada taraf 0,05 . Hasil analisa data menunjukkan bahwa kelas eksperimen memiliki nilai rata-rata ranah kognitif 81,25 sedangkan kelas kontrol meliki rata-rata ranah kognitif 73,88 . Perhitungan $t$ ranah kognitif diperoleh $\mathrm{t}_{(95)(62)}$ yaitu 1,66. Dengan demikian hipotesis yang dikemukakan sebelumnya dapat diterima pada taraf kepercayaan 95\%.Berdasarkan hal tersebut dapat disimpulkan bahwa penerapan pembelajaran aktif tipe Hollywood Squares menggunakan LKS dapat meningkatkan hasil belajar geografi kelas XI IPS SMAN 1 Sutera Kabupaten Pesisir Selatan.
\end{abstract}

Kata Kunci : Pembelajaran Aktif, Hollywood Squares, LKS, Hasil Belajar

\begin{abstract}
The purpose of the research to determine the effect of the application of active learning type of Hollywood Squares using LKS to the results of learning geography students class XI IPS SMAN 1 Sutera Pesisir Selatan Regency. The hypothesis in this study is "There is a significant influence on the application of active learning of the type of Hollywood Squares using LKS to the students' geography result of grade XI SMAN 1 Sutera Pesisir Selatan Regency". This type of research is quasi-experimental, with randomized control only design. The population in this study were students of class XI IPS SMAN 1 Sutera Pesisir Selatan Regency enrolled in the 2016/2017 academic year, selected sample using cluster random sampling technique, which selected XI IPS2 class as control class and class XI IPS1 as experiment class. To test the hypothesis used two equality test ( $t)$ at the 0.05 level.The result of the data analysis shows that the experimental class has an average value of cognitive domain of 81.25 while the control class has a mean of cognitive domain of
\end{abstract}

\footnotetext{
${ }^{1}$ Mahasiswa Program Studi Pendidikan Geografi untuk Wisuda September 2017

${ }^{2}$ Dosen Jurusan Geografi Fakultas Ilmu Sosial Universitas Negeri Padang
} 
73.88. The calculation of the cognitive sphere $t$ obtained (95) (62) is 1.66. Thus the hypothesis presented earlier can be accepted at 95\% confidence level. Based on this it can be concluded that the application of active learning type Hollywood Squares using LKS can improve learning outcomes geography class XI IPS SMAN 1 Sutera Pesisir Selatan Regency.

Key Words: Active Learning, Hollywood Squares, LKS, Learning Outcomes

\section{PENDAHULUAN}

Kurikulum ini menuntut siswa terlibat aktif baik secara fisik maupun mental dan diberi peluang untuk berinteraksi dengan subjek materi sehingga mereka dapat menkontruksi pengetahuan baru secara mandiri, sehingga pembelajaran menjadi lebih bermakna dan mudah dikuasai.

Pembelajaran aktif sangat dibutuhkan dalam segala mata pelajaran tanpa kecuali mata pelajaran geografi. Menurut Lobeck (1939) menyatakan geografi adalah suatu studi tentang hubungan-hubungan yang ada antara kehidupan dengan lingkungan. Geografi sebagai bagian dari mata pelajaran sosial dapat mengembangkan berpikir analitis induktif dan deduktif dalam menyelesaikan masalah yang berkaitan dengan peristiwa alam sekitar.Penyelesaian tersebut dapat berupa kualitatif maupun kuantitatif. Pembelajaran geografi diarahkan untuk "mencari tahu" dan berbuat sehingga dapat membantu siswa untuk memperoleh pemahaman yang lebih mendalam tentang alam sekitar.

Kondisi proses belajar mengajar geografi di sekolah-sekolah, salah satunya SMA N 1 Sutera Kabupaten Pesisir Selatan belum terlaksana seperti yang diharapkan. Metode pembelajar-an geografi yang digunakan oleh guru masih satu arah yaitu pemberian informasi dari guru kepada siswa. Siswa belum terlibat aktif dalam proses pembelajaran, siswa hanya mencatat dan mendengarkan apa yang disampai-kan guru. Keadaan ini menyebabkan siswa kurang aktif karena tidak adanya tantangan dari guru sehubungan dengan materi yang diberikan.Ini berarti pengelolaan kelas masih terfokus pada guru (teacher center) sebagai sumber informasi dan pengetahuan oleh guru, menyebabkan siswa cendrung menghafal materi. Padahal pengetahuan yang didapat siswa dengan menghadapkan siswa pada objek nyata dalam pembelajaran, akan lebih mudah siswa memahami suatu konsep dibanding pengetahuan yang ditransfer begitu saja oleh guru.

Untuk dapat mengerti geografi secara luas, harus dimulai dengan kemampuan pemahaman konsep dasar yang ada pada materi geografi.Berhasil atau tidaknya seorang siswa dalam memahami materi pelajaran geografi sangat ditentukan oleh pemahaman konsep.Jadi bukan hal yang mengejutkan jika hasil belajar geografi siswa relatif rendah.Hal ini terlihat dari nilai rata-rata ujian MID mata pelajaran Geografi siswa kelas XI IPS tahun 2016/2017. 
Tabel 1. Nilai Ketuntasan Ujian MID

Semester 2 Kelas XI IPS SMAN 1

Sutera Kabupaten Pesisir Selatan

Tahun Ajaran 2016/2017

\begin{tabular}{|c|c|c|c|c|c|c|}
\hline \multirow{4}{*}{ Kelas } & \multirow{4}{*}{$\begin{array}{c}\text { Jumlah } \\
\text { Siswa }\end{array}$} & \multicolumn{5}{|c|}{ Persentase Siswa } \\
\hline & & \multirow{3}{*}{$\begin{array}{c}\text { Jumlah } \\
\text { Siswa }\end{array}$} & \multirow{2}{*}{ Tuntas } & \multirow{3}{*}{$\begin{array}{c}\text { Jumlah } \\
\text { Siswa }\end{array}$} & Tidak & \multirow{3}{*}{$\begin{array}{l}\mathrm{K} \\
\mathrm{K} \\
\mathrm{M}\end{array}$} \\
\hline & & & & & Tuntas & \\
\hline & & & $(\%)$ & & $(\%)$ & \\
\hline XI IPS & 32 & 6 & 0,802 & 26 & 81.25 & 80 \\
\hline XI IPS & 32 & 4 & 12.50 & 28 & 87.50 & 80 \\
\hline XI IPS & 32 & 2 & 06.25 & 30 & 93.75 & 80 \\
\hline XI IPS & 25 & 2 & 08.00 & 23 & 92.00 & 80 \\
\hline
\end{tabular}

(Sumber: Guru Geografi Kelas XI IPS SMAN

1 Sutera Kabupaten Pesisir Selatan)

Berdasarkan nilai ujian MID semester 2 kelas XI IPS SMAN 1 Sutera Kabupaten Pesisir Selatan tahun ajaran 2016/2017 memperlihatkan bahwa nilai rata-rata geografi siswa belum memenuhi KKM yang ditetapkan sekolah yaitu 80,00 . Berdasarkan pengamatan yang di-lakukan peneliti, masalah ini disebabkan oleh beberapa faktor, yaitu: (1) Lingkungan dan proses pembelajar-an geografi kurang kondusif. Siswa kurang didorong untuk mengembang-kan kemampuan berfikir, pembelajaran cenderung bersifat menghafal tanpa memahami suatu informasi dan pe-nerapannya dalam kehidupannya sehingga pemahaman itu tidak tinggal lama di ingatan. (2) Pembelajaran masih terpusat kepada guru sedangkan siswa tidak dilibatkan secara aktif dalam pembelajaran. Hal ini me-nyebabkan rendahnya pemahaman siswa, juga membuat rendahnya minat dan motivasi belajar siswa. (3) Guru masih belum maksimal melaksanakan kegiatan peninjauan kembali atau peninjauan ulang, umumnya guru langsung menyimpulkan pokok-pokok materi pelajaran tanpa adanya interaksi dengan siswa. Hal ini menyebabkan siswa seolah-olah tidak dilatih untuk bertanggung jawab terhadap apa yang dipelajarinya.
Dari beberapa masalah yang dipaparkan di atas, keterlibatan siswa secara aktif sangat diperlukan agar siswa dapat memahami konsep pelajaran lebih mendalam.Untuk mencapai tujuan tersebut maka guru sebagai fasilitator dan pembimbing harus mampu menyusun dan merencanakan program pengajaran yang baik dan tepat. Untuk meningkatkan efektifitas proses pembelajaran, dapat dilakukan dengan peninjauan ulang atau penjangkaran pada akhir setiap sesi pembelajaran sekaligus membuat kesimpulan dari apa yang telah dipelajari.

Untuk mengatasi masalah yang dikemukakan diatas dapat digunakan strategi pembelajaran aktif (active learning).Strategi ini merupakan salah satu strategi pembelajaran yang melibatkan mental dan kinerja siswa sendiri. Siswa harus menggunakan otak, mengkaji gagasan, memecahkan masalah dan menerapkan apa yang telah dipelajari. Belajar aktif harus gesit, menyenangkan, bersemangat dan penuh gairah. Tingginya tingkat keaktifan dan motivasi siswa dalam belajar akan mempengaruhi hasil belajar. Disamping itu, pada saat proses pembeajaran berlangsung, siswa dapat menyelesaikan soal-soal ataupun masalah-masalah baik berupa konsep maupun pembahasan secara matematis yang tersaji pada LKS. Menurut Diknas (2005 :5) Lembar Kegiatan Siswa adalah lembaranlembaran berisi tugas yang harus dikerjakan oleh peserta didik. LKS akan memuat paling tidak judul, kompetensi dasar yang akan dicapai, waktu penyelesaian tugas, informasi singkat,langkah-langkah kerja, tugas yang harus dilakukan dan laporan yang harus dikerjakan.

Untuk meningkatkan efektifitas proses pembelajaran, dapat dilakukan 
dengan peninjauan ulang atau penjangkaran pada akhir setiap sesi pembelajaran dan sekaligus membuat kesimpulan dari apa yang telah dipelajari. Proses pengulangan atau peninjauan kembali sangat penting dilakukan dengan meluruskan konsepkonsep pelajaran yang kurang tepat serta bermanfaat untuk meningkatkan daya ingat siswa. Hal ini sejalan dengan pendapat Silberman (2006: 249) yang menyatakan bahwa "salah satu cara yang pasti membuat pembelajaran tetap melekat dalam pikiran adalah mengalokasikan waktu untuk peninjauan kembali apa yang telah dipelajari. Materi yang telah dibahas oleh siswa cendrung lima kali melekat dalam pikiran dibandingkan materi yang tidak".

Menurut Silberman (2006: 267) salah satu belajar aktif dapat digunakan dalam pengulangan adalah strategi belajar tipe Hollywood Squares. Penerapan strategi ini akan membantu siswa untuk mengingat kembali materi yang telah dipelajari. Menurut tipe Hollywood Squres, dalam suatu kegiatan tertentu beberapa siswa diberikan peran yang berbeda satu sama lain, ada siswa berperan sebagai contestan yaitu siswa yang mengaju-kan pertanyaan, siswa yang bertindak sebagai celebrity squares ini semua siswa mempunyai tugas masing-masing agar terlibat dalam permainan.

Berdasarkan latar belakang di atas akan dilakukan suatu penelitian tentang "Pengaruh Penerapan Pembelajaran Aktif Tipe Hollywood Squares Menggunakan LKS Terhadap Hasil Belajar Geografi Siswa Kelas XI IPS SMAN I Kabupaten Pesisir Selatan".

\section{METODE PENELITIAN}

Penelitian ini adalah penelitian eksperimen semu (Quasi Experimenth Research).Desain ini mempunyai kelompok kontrol namun tidak dapat berfungsi sepenuhnya untuk mengontrol variabel-variabel luar yang mempengaruhi pelaksanaan eksperimen. Rancangan yang digunakan adalah Randomized Control Group Only Design.Dalam penelitian ini, sampel diperlukan dua kelompok yaitu kelas eksperimen dan kelas kontrol. Pada kelas eksperimen diberikan perlakuan berupa penerapan strategi active learning tipe Hollywood Squares menggunakan LKS, sedang-kan pada kelas kontrol dilakukan pembelajaran biasa yang berlaku di sekolah.

Populasi merupakan objek atau subjek yang berada pada suatu wilayah dan memenuhi syarat-syarat tertentu berkaitan dengan masalah penelitian.Sugiyono menerangkan populasi adalah objek/subjek yang mempunyai kuantitas dan karakteristik tertentu yang ditetapkan oleh peneliti untuk dipelajari dan kemudian ditarik kesimpulannya. Populasi dalam penelitian ini adalah seluruh siswa kelas XI IPS SMA N 1 Sutera Kabupaten Pesisir Selatan yang terdaftar pada tahun pelajaran 2016/2017 yang berjumlah 121 orang dan terdistribusikan dalam empat kelas yaitu kelas XI IPS ${ }_{1}-\mathrm{XI} \mathrm{IPS}_{2}-\mathrm{XI}$ $\mathrm{IPS}_{3-X I} \mathrm{IPS}_{4}$.

Sampel adalah sebagian atau wakil populasi yang di teliti (Sugiyono 2010:118).Sampel yang diambil dari populasi harus representative (mewakili). Teknik sampling dalam penelitian ini adalah cluster random sampling (teknik acak berkelompok). Populasi yang ada di ambil dua kelompok sampel yaitu sebagai kelas 
eksperimen dan sebagai kelas kontrol.Ternyata yang menjadi kelas eksperimen adalah kelas XI IPS ${ }_{1}$ dan kelas kontrol XI IPS 2 .

Analisa data yang digunakan untuk menganalisa data dalam penelitian ini adalah analisa yang dilakukan dalam analisis data ini adalah : (1) Uji Normalitas ; (2) Uji Homogenitas ; (3) Uji Hipotesis.

\section{HASIL DAN PEMBAHASAN}

Penelitian dilakukan di SMAN 1 Sutera Kabupaten Pesisir Selatan pada kelas XI tahun ajaran 2016/2017 pada mata pelajaran geografi. Objek pada penelitian ini adalah kelas XI IPS sebagai kelas Eksperimen dan kelas XI IPS 2 sebagai kelas Kontrol.Tema pembelajaran yang di ajarkan dalam penelitian ini adalah Menganalisis pelestarian lingkungan hidup dalam kaitannya dengan pembangunan berkelanjutan. Pada kelas eksperimen di lakukan tiga kali pertemuan dan pada kelas kontrol di lakukan tiga kali pertemuan yang di bedakan hanya metodenya saja

Data dalam penelitian ini diperoleh langsung dari kelas sampel berupa hasil belajar pada ranah kognitif.Data diambil dengan mengadakan tes tertulis berupa pilihan ganda dengan jumlah soal 25 butir.Nilai hasil tes diperoleh dari kelas eksperimen dan kontrol. Tes hasil belajar pada kelas eksperimen diikuti oleh 32 orang siswa dan kelas kontrol 32 orang siswa. Hasil tersebut dapat dilihat pada tabel 1
Tabel 1. Hasil Tes Akhir Kelas Eksperimen dan Kontrol

\begin{tabular}{|c|c|c|c|c|}
\hline \multicolumn{3}{|c|}{ Kelas Kontrol } & \multicolumn{2}{|c|}{$\begin{array}{c}\text { Kelas } \\
\text { Eksperimen }\end{array}$} \\
\hline No & Nilai & $\begin{array}{l}\text { Jumlah } \\
\text { Siswa }\end{array}$ & Nilai & $\begin{array}{c}\text { Jumlah } \\
\text { Siswa }\end{array}$ \\
\hline 1 & 56 & 3 & 68 & 3 \\
\hline 2 & 60 & 4 & 72 & 4 \\
\hline 3 & 64 & 4 & 76 & 4 \\
\hline 4 & 68 & 2 & 80 & 6 \\
\hline 5 & 76 & 3 & 84 & 4 \\
\hline 6 & 80 & 8 & 88 & 4 \\
\hline 7 & 84 & 3 & 92 & 5 \\
\hline 8 & 88 & 4 & 96 & 2 \\
\hline 9 & 92 & 1 & & \\
\hline $\begin{array}{l}\text { Nilai } \\
\text { Min }\end{array}$ & 56 & & 68 & \\
\hline $\begin{array}{l}\text { Nilai } \\
\text { Max }\end{array}$ & 92 & & 96 & \\
\hline \multicolumn{2}{|c|}{$\mathrm{KKM}$} & 80 & KKM & 80 \\
\hline \multirow{2}{*}{\multicolumn{2}{|c|}{$\begin{array}{l}\text { Ketuntasan } \\
\text { dan } \\
\text { persentase }\end{array}$}} & $\begin{array}{c}\text { Tuntas } 13 \\
\text { siswa } \\
(40.62 \%) \\
\end{array}$ & \multicolumn{2}{|c|}{$\begin{array}{c}\text { Tuntas } 21 \text { siswa } \\
(65.63 \%)\end{array}$} \\
\hline & & $\begin{array}{c}\text { Tidak } \\
\text { tuntas } 19 \\
\text { siswa } \\
(59.38 \%)\end{array}$ & \multicolumn{2}{|c|}{$\begin{array}{l}\text { Tidak tuntas } 11 \\
\text { siswa }(34.37 \%)\end{array}$} \\
\hline \multicolumn{2}{|c|}{$\overline{\mathrm{X}}$} & 73.88 & \multicolumn{2}{|c|}{81.25} \\
\hline \multicolumn{2}{|c|}{$\mathrm{S}^{2}$} & 126.95 & \multicolumn{2}{|c|}{71.16} \\
\hline \multicolumn{2}{|c|}{$\mathrm{S}$} & 11.27 & \multicolumn{2}{|c|}{8.44} \\
\hline
\end{tabular}

Tabel 1 menyajikan informasi lengkap yang dapat membedakan hasil belajar Geografi siswa antara kelas eksperimen dan kelas kontrol berdasarkan statistik deskriptif, untuk materi pemanfaatan lingkungan hidup dalam pembangunan. Berdasarkan tabel 9 diketahui bahwa pada kelas eksperimen, nilai terendah yang diperoleh siswa adalah 68, sedangkan nilai tertingginya adalah 96, dan siswa yang memperoleh nilai dibawah kriteria ketuntasan minimal (KKM) sebanyak 11 orang (34.37\%) sedangkan siswa yang memperoleh nilai diatas KKM sebanyak 21 orang $(65.63 \%)$. Rata-rata hasil belajar kelas eksprimen adalah 81.25, sedangkan simpangan baku/standar deviasi (S) adalah 8.44beserta $\operatorname{ragamnya}\left(\mathrm{S}^{2}\right)$ adalah 71.16 . 
Selain menyajikan data tentang kelas eksperimen, tabel 9 juga menyajikan informasi statistik desriptif tentang kelas kontrol. Dari tabel diketahui bahwa nilai terendah yang diperoleh siswa adalah 56 dan nilai tertingginya adalah 92.Siswa yang mendapatkan nilai dibawah KKM sebanyak 19 siswa (59.38\%)sedangkan siswa yang memperoleh nilai diatas KKM sebanyak 13siswa (40.62\%).Rata-rata hasil belajar kelas kontrol adalah 73.88, sedangkan simpangan baku/standar deviasi (S) adalah 11.27 beserta ragamnya $\left(S^{2}\right)$ adalah 126.95 .

Analisis data dilakukan untuk menguji kebenaran hipotesis yang diajukan dalam penelitian ini. Hipotesis dalam penelitian ini adalah dengan menerapkan.Untuk mengetahui apakah hipotesis ini diterima atau ditolak maka hasil belajar geografi siswa pada kelas eksperimen dengan hasil belajar geografi siswa pada kelas kontrol dilakukan analisis data sebagai berikut :Syarat untuk menguji hipotesis terlebih dahulu dilakukan uji normalitas dan uji homogenitas terhadap hasil belajar kelas eksperimen dan kelas kontrol.

Uji normalitas bertujuan untuk melihat apakah sampel berdistribusi normal atau tidak.Untuk menguji normalitas digunakan ujiLilifors. Kriteria pada uji Lilifors ini adalah $\mathrm{H}_{0}$ akan diterima jika $\mathrm{L}_{0}<\mathrm{L}_{\mathrm{t}}$ berdasarkan langkah-langkah uji Lilifors maka didapatkan hasil perhitungan uji normalitas kelas eksperimen dengan $\mathrm{L}_{0}=0.1145$ dan $\mathrm{L}_{\mathrm{t}}$ $=0.157$. Normalitas pada kelas kontrol juga di uji Lilifors didapatkan $\mathrm{L}_{0}=0.1544$ dan $\mathrm{L}_{\mathrm{t}}=0.157$.

Hasil uji normalitas sampel diperoleh bahwa pada kelas eksperimen diperoleh Lo < $\mathrm{L}_{\text {tabel }}$ sehingga dapat diambil kesimpulan kelas eksperimen berdistribusi normal. Untuk kelas kontrol diperoleh $\mathrm{Lo}<\mathrm{L}_{\text {tabel }}$ sehingga kelas kontrol berasal dari populasi yang berdistribusi normal.

Uji homogenitas ini bertujuan untuk melihat apakah kedua kelas sampel mempunyai varians yang homogen atau tidak. Kriteria pengujian, jika $F_{\text {hitung }}<F_{\text {tabel }}$,maka kedua sampel mempunyai varians yang homogen.

Hasil uji homogenitas sampel diperoleh $\mathrm{F}_{\text {hitung }}=0.56$ dan $\mathrm{F}$ tabel $=1.83$ pada taraf nyata $0.05, \mathrm{dk}_{1}=31$ dan $\mathrm{dk}_{2}=31$. Hal ini menunjukkan bahwa $F_{\text {hitung }}<F_{\text {tabel. }}$. Dengan demikian dapat disimpul kan bahwa antara kelas eksperimen dan kelas kontrol mempunyai variansi yang homogen.Setelah melakukan uji normalitas dan uji homogenitas, ternyata hasil tes akhir pada kedua kelas sampel berasal dari populasi berdistribusi normal dan mempunyai varians yang homogen.

Analisis uji-t tes akhir di kelas eksperimen diperoleh $t_{\text {hitung }}=3.16$ sedangkan dari tabel nilai $t_{\text {tabel }}(0,95)(62)$ $=1.66$ pada taraf nyata 0,05 pada taraf kepercayaan 95\%. Berdasarkan data diatas $t_{\text {hitung }}>t_{\text {tabel }}$ yaitu $3.16>1.66$ pada taraf nyata 0,05 pada taraf kepercayaan 95\%. Maka $\mathrm{H}_{0}$ ditolak dan $\mathrm{H}_{1}$ diterima.Hal ini berarti bahwa terdapat peningkatan hasil belajar geografi yang diajarkan dengan Penerapan Pembelajaran Aktif Tipe Hollywood Squares Menggunakan LKS Terhadap Hasil Belajar Geografi Siswa Kelas XI IPS SMAN I Sutera Kabupaten Pesisir Selatan.

Hasil deskripsi data diperoleh bahwa rata-rata kelas eksperimen adalah 81.75 dan rata-rata kelas kontrol adalah 73.88 terlihat rata-rata 
kelas eksperimen lebih tinggi dari pada rata-rata kelas kontrol, dari uji hipotesis ternyata terdapat peningkatan hasil belajar yang berarti. Dengan demikian dapat disimpulkan bahwa dengan adanya Pengaruh Penerapan Pembelajaran Aktif Tipe Hollywood Squares Menggunakan LKS Terhadap Hasil Belajar Geografi Siswa Kelas XI IPS SMAN I Sutera Kabupaten Pesisir Selatan.

\section{KESIMPULAN DAN SARAN}

Setelah dilakukan analisis dan pembahasan terhadap masalah yang telah dilakukan dalam penelitian, maka dapat diambil kesimpulan bahwa hasil belajar geografi siswa pada kelas eksperimen lebih tinggi dari pada hasil belajar geografi kelas kontrol. Ini terlihat dari rata-rata hasil belajar geografi siswa pada kelas eksperimen 81,75 dan rata-rata kelas kontrol 73,88. Ditinjau dari segi ketuntasan belajar, pada kelas eksperimen.

Perbedaan ini diyakini akibat pengaruh perlakuan yang diberikan kelas eksperimen.Dengan demikian dapat dinyatakan bahwa terdapat pengaruh penerapan pembelajaran aktif tipe Hollywood Squares menggunakan LKS terhadap hasil belajar geografi siswa kelas XI IPS SMAN 1 Sutera Kabupaten Pesisir Selatan.

Berdasarkan kesimpulan penelitian ini, maka penulis menyarankan

1. Dapat digunakan sebagai alternative bagi guru-guru dalam usaha meningkatkan aktivitas siswa dan penguasaan konsep pada mata pelajaran geografi.

2. Kepala Sekolah / Wakil Kurikulum yang terkait agar dapat menerapkan pembelajaran aktif tipe Hollywood Squarespada setiap materi ajar lain, khususnya pada mata pelajaran geografi dan mata pelajaran umum lainnya.

3. Diharapkan ada penelitian lebih lanjut dengan materi geografi lainnya.

4. Mengadakan seminar terbuka disekolah tentang model pembelajaran Hollywood Squares

\section{DAFTAR PUSTAKA}

Depdiknas (2003).Pedoman Khusus Pengembangan Silabus dan Penilaian. Jakarta : Badan Nasional Menengah Umum.

Depdiknas (2005).Lembar Kerja Siswa.Jakarta: Direktorat Pendidikan menengah Umum

Depdiknas (2006).Pedoman Khusus Pengembangan Silabus dan Contoh / Model Silabus. Jakarta : Badan Standar Nasional Pendidikan.

Depdiknas (2004).Pedoman Umum Pengembangan Bahan Ajar Sekolah Menengah Atas. Jakarta : Badan Standar Nasional Pendidikan

Silberman, Melvin L.2006. Active Learning 101 cara belajar siswa aktif. Bandung : Nusamedia dan Nuansa .

Suharsimi Arikunto (2005). Dasardasar Evaluasi Pendidikan. Jakarta : Erlangga. 